\title{
Younger Age Predicts Failure to Achieve Viral Suppression and Virologic Rebound Among HIV-1-Infected Persons in Serodiscordant Partnerships
}

\author{
Andrew Mujugira, ${ }^{1,2}$ Connie Celum, ${ }^{1-3}$ Jordan W. Tappero, ${ }^{4}$ Allan Ronald, \\ Nelly Mugo, ${ }^{1,6}$ and Jared M. Baeten ${ }^{1-3}$
}

\begin{abstract}
Background: Antiretroviral therapy (ART) markedly reduces the risk of HIV-1 transmission in serodiscordant partnerships. We previously found that younger age and higher CD4 counts were associated with delayed initiation of ART by HIV-1-infected partners in serodiscordant partnerships. Among those initiating ART, we sought to explore whether those same factors were associated with failure to achieve viral suppression.

Methods: In a prospective study of HIV-1-infected persons who had a known heterosexual HIV-1-uninfected partner in Kenya and Uganda [Partners Pre-Exposure Prophylaxis (PrEP) Study], we used Cox proportional hazards regression to evaluate correlates of viral nonsuppression (HIV-1 RNA >80 copies $/ \mathrm{ml}$ ).

Results: Of 1,035 HIV-1-infected participants initiating ART, 867 (84\%) achieved viral suppression: $77 \%$ by 6 months and $86 \%$ by 12 months. Younger age [adjusted hazard ratio (aHR) 1.05 for every 5 years younger; $p=.006$ ], lower pretreatment CD4 count (aHR 1.26; $p=.009$ for $\leq 250$ compared with $>250$ cells $/ \mu$ l), and higher pretreatment HIV-1 RNA quantity (aHR 1.21 per $\left.\log _{10} ; p<.001\right)$ independently predicted failure to achieve viral suppression. Following initial viral suppression, 8.8\% (76/867) experienced virologic rebound (HIV-1 RNA > 200 copies $/ \mathrm{ml}$ ): $6.3 \%$ and $11.5 \%$ by 6 and 12 months after initial suppression, respectively. Age was the only factor associated with increased risk of virologic rebound (aHR 1.33 for every 5 years younger; $p=.005$ ). Conclusions: For HIV-1-infected persons in serodiscordant couples, younger age was associated with delayed ART initiation, failure to achieve viral suppression, and increased risk of virologic rebound. Motivating ART initiation and early adherence is a key to achieving and sustaining viral suppression.
\end{abstract}

\section{Introduction}

T HeRE WERE AN ESTIMATED 1.5 million new HIV-1 infections in sub-Saharan Africa in 2013, most of which were sexually transmitted. ${ }^{1}$ The major determinant of sexual HIV-1 transmission risk is the concentration of HIV-1 RNA in plasma and genital secretions, ${ }^{2,3}$ and antiretroviral therapy (ART), which suppresses systemic and genital HIV-1 replication decreases sexual HIV-1 transmission by $>90 \%$. ${ }^{4,5}$ The World Health Organization (WHO) recommends ART initiation regardless of CD4 count for HIV-1-infected persons with uninfected partners to prevent sexual transmission of HIV $-1 .^{6}$ Achieving and sustaining viral load suppression is a key outcome of the HIV-1 treatment continuum and is critical to the success of ART for HIV-1 prevention.
The concentration of HIV-1 RNA in plasma is the principal indicator of ART prevention effectiveness. Nonadherence to ART increases the likelihood of poor virologic outcomes, including viral nonsuppression, virologic rebound, disease progression, and HIV-1 transmission, including transmission of drug-resistant virus. ${ }^{7,8}$ In resourcerich settings, younger age predicts nonadherence, viral nonsuppression, virologic rebound, and loss to follow-up. ${ }^{9}$ Correlates of ART nonadherence include lower income, depression, alcohol and substance use, and lack of social support. ${ }^{10-14}$ Nonadherence also occurs when asymptomatic individuals on ART skip doses or stop treatment completely because they feel well. ${ }^{15}$ As ART for HIV-1 prevention is scaled-up, and ART is prescribed to healthy individuals with higher CD4 counts more generally, it will

Departments of ${ }^{1}$ Global Health, ${ }^{2}$ Epidemiology, and ${ }^{3}$ Medicine, University of Washington, Seattle, Washington.

${ }^{4}$ Division of Global Health Protection, Center for Global Health, Centers for Disease Control and Prevention, Atlanta, Georgia.

${ }^{5}$ Departments of Medicine and Medical Microbiology, University of Manitoba, Winnipeg, Canada.

${ }^{6}$ Center for Clinical Research, Kenya Medical Research Institute, Nairobi, Kenya. 
be critical to understand and address preventable factors related to viral nonsuppression.

We previously reported that younger individuals and persons with higher CD4 counts in HIV-1 serodiscordant partnerships in Kenya and Uganda were more likely to delay ART initiation. ${ }^{16}$ In this study, we evaluated correlates of nonsuppression among the subset of HIV-1-infected partners who initiated ART. We sought to evaluate whether factors that predicted delay in ART initiation were similarly related to failure to achieve viral suppression and virologic rebound after initial suppression.

\section{Materials and Methods}

\section{Study cohort and procedures}

We conducted a prospective study among HIV-1-infected partners in HIV-1 serodiscordant couples enrolled in the Partners Pre-Exposure Prophylaxis (PrEP) Study, a randomized clinical trial of daily oral PrEP to decrease HIV-1 acquisition among HIV-1-uninfected members of serodiscordant couples (ClinicalTrials.gov NCT00557245). ${ }^{17}$ Between 2008 and 2012, a total of 4,747 heterosexual HIV-1 serodiscordant couples were followed at nine research sites in Kenya and Uganda. HIV-1-uninfected partners were randomly assigned to daily oral PrEP or placebo and followed monthly for up to 36 months. At the time of enrollment, HIV1-infected partners were not eligible for ART according to Kenya and Uganda national guidelines, which early in the study recommended ART only for those with symptomatic HIV-1 disease or CD4 counts $<250$ cells $/ \mu$ l and were subsequently revised to CD4 counts $\leq 350$ cells $/ \mu$ in July 2010 (Kenya) and April 2012 (Uganda). HIV-1-infected participants were followed quarterly and received regular clinical monitoring. Those who became eligible during follow-up for ART were referred to partnering HIV-1 care programs. ART and adherence counseling were provided by referral partners or at on-site clinics affiliated to the site organization. All participants received HIV-1 prevention services, including regular individual and couple HIV-1 counseling, condoms, risk reduction counseling, plus syndromic or etiologic diagnosis, and treatment for sexually transmitted infections.

CD4 testing was performed at baseline and every 6 months thereafter at study site laboratories using the BD FACSCalibur or BD FACSCount instrumentation (BD Biosciences). ${ }^{18}$ Plasma for HIV-1 RNA quantification was collected at enrollment and every 6 months thereafter and archived and batch tested at the University of Washington after the end of the study using the Abbott m2000 Real-Time HIV-1 RNA assay (Abbott); the lower limit of quantification was 80 copies/ml. Viral load testing was not standard of care, and results were not available until after the study ended.

\section{Statistical analyses}

Participants were included in the analyses if they initiated ART during study follow-up, had a pre-ART plasma HIV-1 RNA concentration $>80$ copies $/ \mathrm{ml}$, and had at least one HIV-1 RNA quantification after starting treatment. Failure to achieve viral suppression (the primary outcome) was defined as plasma HIV-1 RNA concentration $>80$ copies $/ \mathrm{ml}$. We used a Cox proportional hazards regression model to assess factors related to viral nonsuppression. Baseline factors evaluated included age, gender, years of education, duration of partnership and known HIV-1 serodiscordant status, monthly income, alcohol use, pretreatment CD4 count, and HIV-1 RNA concentration. Unprotected sex in the prior month and pregnancy were evaluated as time-varying covariates. Factors with $p \leq .20$ in bivariate analyses were included in multivariate models. In sensitivity analyses, we repeated our primary analysis by including subjects who achieved viral suppression before reporting ART use (although this potentially indicated unreported ART use before first reporting having started $\mathrm{ART}^{19}$ ) and by using a different cutoff (HIV-1 RNA concentration $>400$ copies $/ \mathrm{ml}$ ) to define viral nonsuppression. In addition, we assessed factors associated with virologic rebound, which we defined as HIV-1 RNA concentration $>200$ copies $/ \mathrm{ml}$ following initial viral suppression. Statistical analyses were performed using SAS version 9.3 and Stata 12.1.

\section{Ethical approval}

The Partners PrEP Study was approved by the University of Washington Human Subjects Review Committee and ethics review committees at all collaborating institutions. All participants provided written informed consent.

\section{Results}

\section{Participant characteristics}

Of the 4,747 HIV-1-infected participants enrolled and followed in the Partners PrEP Study, 1,817 initiated ART during study follow-up, of whom 1,035 (57\%) were included in the primary analysis (Fig. 1). The median age was 35 years [interquartile range (IQR) 28-41] and 560 (54\%) were women (Table 1). Most (98\%) were married or cohabiting with their HIV-1-uninfected partner. The median duration of partnership was 9 years (IQR 3-16), and 263 (26\%) reported having unprotected sex with the study partner at enrollment. The median body mass index was $22 \mathrm{~kg} / \mathrm{m}^{2}$ (IQR 20-24) for women and $21 \mathrm{~kg} / \mathrm{m}^{2}$ (IQR 20-23) for men. Women had higher median pre-ART CD4 counts than men (260 vs. 246 cells $\mu \mathrm{l} ; \quad p<.0001)$. The median HIV-1 RNA plasma

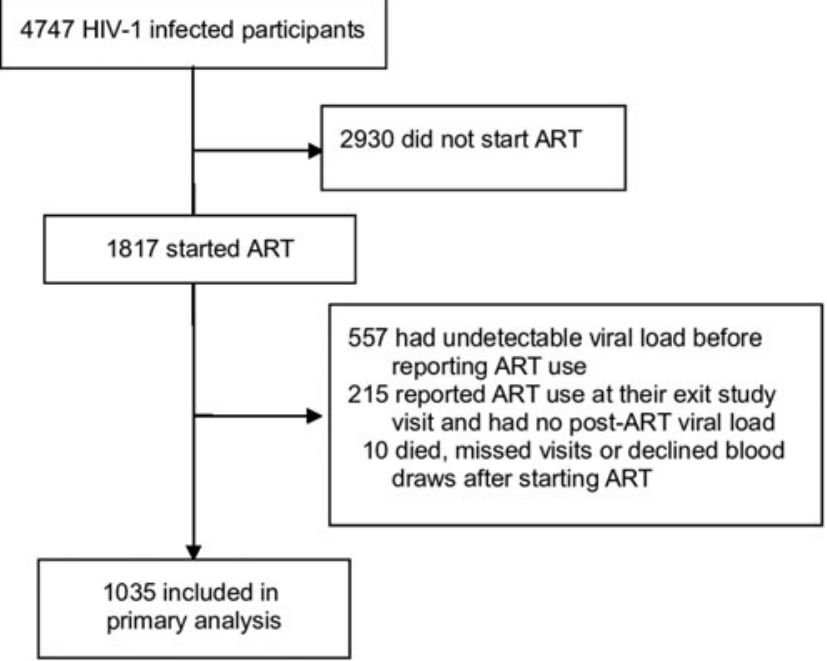

FIG. 1. Study profile. ART, antiretroviral therapy. 
Table 1. Participant Characteristics and Factors Associated with Viral Nonsuppression

\begin{tabular}{|c|c|c|c|c|c|}
\hline Covariate & $\begin{array}{c}\mathrm{n}(\%) \text { or } \\
\text { median }(I Q R)\end{array}$ & $\begin{array}{l}\text { Hazard ratio } \\
(95 \% \mathrm{CI})\end{array}$ & $\mathrm{p}$ & $\begin{array}{l}\text { Adjusted hazard } \\
\text { ratio }(95 \% \mathrm{CI})\end{array}$ & $\mathrm{p}$ \\
\hline Age (per 5 years younger) & $35(28-41)$ & $1.05(1.01-1.09)$ & .01 & $1.05(1.04-1.10)^{\mathrm{a}}$ & .006 \\
\hline $\begin{array}{l}\text { Gender } \\
\text { Women } \\
\text { Men }\end{array}$ & $\begin{array}{l}560(54) \\
475(46)\end{array}$ & $\begin{array}{c}\text { Referent } \\
0.97(0.85-1.10)\end{array}$ & .63 & & \\
\hline $\begin{array}{l}\text { Partnership duration (years) } \\
\quad \geq 1 \\
\quad<1\end{array}$ & $\begin{array}{c}961(93) \\
74(7)\end{array}$ & $\begin{array}{c}\text { Referent } \\
1.19(0.91-1.56)\end{array}$ & .19 & $\begin{array}{c}\text { Referent } \\
1.19(0.91-1.55)\end{array}$ & .21 \\
\hline $\begin{array}{l}\text { Known HIV discordance (y } \\
\quad \geq 1 \\
\quad<1\end{array}$ & $\begin{array}{l}430(42) \\
605(58)\end{array}$ & $\begin{array}{c}\text { Referent } \\
1.06(0.93-1.21)\end{array}$ & .41 & & \\
\hline $\begin{array}{l}\text { Education (years) } \\
\quad>7 \\
\leq 7\end{array}$ & $\begin{array}{l}396(38) \\
639(62)\end{array}$ & $\begin{array}{c}\text { Referent } \\
1.02(0.89-1.17)\end{array}$ & .74 & & \\
\hline $\begin{array}{l}\text { Visits at which unprotected } \\
\text { None } \\
\text { Any }\end{array}$ & $\begin{array}{l}\text { acts were reported } \\
1,264(88) \\
169(12)\end{array}$ & $\begin{array}{c}\text { Referent } \\
0.90(0.73-1.10)\end{array}$ & .29 & & \\
\hline $\begin{array}{l}\text { Visits when pregnant } \\
\text { No } \\
\text { Yes }\end{array}$ & $\begin{array}{c}1,363(96) \\
53(4)\end{array}$ & $\begin{array}{c}\text { Referent } \\
1.18(0.82-1.70)\end{array}$ & .37 & & \\
\hline $\begin{array}{l}\text { Children in partnership } \\
\text { Any } \\
\text { None }\end{array}$ & $\begin{array}{l}839(81) \\
196(19)\end{array}$ & $\begin{array}{c}\text { Referent } \\
0.97(0.81-1.14)\end{array}$ & .70 & & \\
\hline $\begin{array}{l}\text { Monthly income } \\
\text { Any } \\
\text { None }\end{array}$ & $\begin{array}{l}727(70) \\
308(30)\end{array}$ & $\begin{array}{c}\text { Referent } \\
0.90(0.77-1.04)\end{array}$ & .14 & $\begin{array}{c}\text { Referent } \\
1.14(0.97-1.33)\end{array}$ & .11 \\
\hline $\begin{array}{l}\text { Alcohol consumption } \\
\text { None } \\
\text { Any }\end{array}$ & $\begin{array}{l}832(80) \\
203(20)\end{array}$ & $\begin{array}{c}\text { Referent } \\
0.94(0.80-1.10)\end{array}$ & .43 & & \\
\hline $\begin{array}{l}\text { Pretreatment CD4 count } \text { (ce } \\
\quad>250 \\
\quad \leq 250\end{array}$ & $\begin{array}{l}500(48) \\
535(52)\end{array}$ & $\begin{array}{c}\text { Referent } \\
1.28(1.12-1.46)\end{array}$ & .003 & $\begin{array}{c}\text { Referent } \\
1.26(1.10-1.45)\end{array}$ & .009 \\
\hline $\begin{array}{l}\text { Pretreatment HIV-1 RNA } \\
\quad\left(\text { per } \log _{10} \text { copies/ml) }\right.\end{array}$ & $4.44(3.90-4.89)$ & $1.23(1.12-1.34)$ & $<.001$ & $1.21(1.11-1.33)$ & $<.001$ \\
\hline
\end{tabular}

${ }^{a}$ The aHR for younger age differed by $<1 \%$ after stratifying by study site (aHR 1.052).

${ }^{\mathrm{b}}$ Pregnancy and unprotected sex were analyzed as time-varying covariates. These are visits at which unprotected sex was reported or the woman was pregnant, and blood was collected for plasma viral load quantification.

aHR, adjusted hazard ratio; CI, confidence interval; IQR, interquartile range.

concentration before ART start was $4.44 \log _{10}$ copies $/ \mathrm{ml}$ (IQR 3.90-4.89): 4.57 and 4.30 $\log _{10}$ copies/ml in men and women, respectively. As previously reported, study retention was high in the Partners PrEP Study, with at least $91 \%$ of HIV-1-infected partners retained at all study visits. ${ }^{20}$

\section{Plasma viral suppression and correlates of nonsuppression}

After ART initiation, HIV-1-infected participants were followed for 467 person-years for the assessment of viral suppression, with a median duration of follow-up of 13.8 months (IQR 7.8-19.4). Overall, 867 (84\%) achieved viral suppression and the median time to first viral suppression was 3.1 months (IQR 2.8-5.6). The cumulative probabilities of achieving viral suppression at 3, 6, 12, and 24 months after starting ART were $46.7 \%, 76.7 \%, 86.0 \%$, and $90.1 \%$, respectively (Fig. 2).
In bivariate analyses, younger age $(p=.01)$, lower CD4 count before treatment initiation $(p=.003)$, and higher pretreatment HIV-1 RNA concentration $(p<.001)$ were significantly associated with viral nonsuppression (Table 1). In the adjusted model, the likelihood of viral nonsuppression increased by $5 \%$ for every 5-year decrease in age [adjusted hazard ratio (aHR) $1.05 ; p<.006]$. Lower pretreatment CD4 count (aHR 1.26 for $\leq 250$ compared with $>250$ cells $/ \mu$; $p=.009$ ) and higher pretreatment HIV-1 RNA concentrations (aHR 1.21 per $\log _{10} ; p<.001$ ) were also significantly associated with failure to achieve viral suppression in plasma.

In sensitivity analyses, with viral nonsuppression defined as HIV-1 RNA >400 copies/ml, our findings were similar to the primary analysis (Table 2). Failure to achieve viral suppression was independently associated with younger age $(p=.01)$, lower pretreatment CD4 count $(p=.004)$, and higher pretreatment HIV-1 RNA quantity $(p=.008)$. Similar findings were obtained when HIV-1-infected persons who 


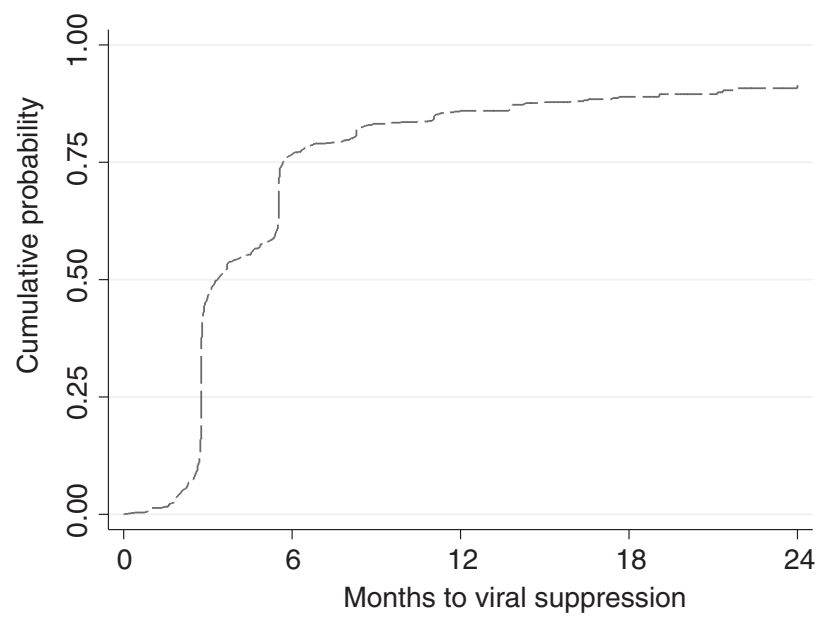

Number at risk 1035 215

90

42

FIG. 2. Time to first viral suppression following ART initiation.

achieved viral suppression before reporting ART use $(n=557$, Fig. 1) were included (Table 2).

\section{Virologic rebound}

The 867 HIV-1-infected partners who achieved viral suppression were followed for 688 person-years for assessment of virologic rebound. Of the 76 persons $(8.8 \%)$ who experienced virologic rebound (HIV-1 RNA >200 copies/ $\mathrm{ml}), 51(67 \%)$ were women. The cumulative probabilities of virologic rebound at 6 and 12 months after viral suppression were $6.3 \%$ and $11.5 \%$, respectively (Fig. 3). The median HIV-1 RNA concentration at the first occurrence of virologic rebound was 1,244 copies/ml (IQR 208-7894); however, $24 \%$ (18/76) subsequently were suppressed (HIV-1 RNA $<80$ copies/ml) before their last study visit.

In bivariate analyses, age [HR 1.35 for every 5 years younger; $95 \%$ confidence interval $(\mathrm{CI}): 1.18-1.54 ; p<.001]$ and female gender (HR 1.95; 95\% CI: $1.20-3.16 ; p=.007$ ) were associated with virologic rebound, but pregnancy

$(p=.31)$ and pretreatment HIV-1 RNA concentrations $(p=.67)$ were not. After adjusting for gender, age remained the only independent predictor of virologic rebound (aHR 1.33 for every 5 years younger; $95 \% \mathrm{CI}: 1.14-1.56 ; p=.005)$; gender was not statistically significant after controlling for age $(p=.8)$.

\section{Discussion}

In this prospective study of $\sim 1,000$ East African HIV-1infected persons in serodiscordant partnerships, nearly all HIV-1-infected persons achieved plasma viral suppression after starting ART. Younger age, lower CD4 count, and higher HIV-1 RNA concentrations at treatment initiation independently predicted failure to achieve viral suppression in plasma. Younger age was the only significant factor associated with virologic rebound after initial viral suppression. In previous work from this cohort, younger age and higher pretreatment CD4 counts predicted delays in ART initiation in the same population. Unique to this population, all individuals initiating ART had a known HIV-1-uninfected partner, and all were counseled about both treatment and prevention benefits of ART.

Younger age has been associated with lower rates of HIV-1 virologic suppression in prior studies. A review of 49,921 HIV-1-infected persons on ART in 33 European cohorts found that increasing age correlated with better virologic outcomes. $^{21}$ A study of $\sim 9,000$ adults on ART in South Africa found lower rates of virologic suppression in younger adults (16-24 years) compared with those aged 25-49 years. ${ }^{22}$ These data suggest that younger age predicts failure to achieve viral suppression and that this risk decreases with age. Younger age is associated with poor ART adherence. ${ }^{23-25}$ Younger age also predicted low PrEP adherence in our cohort. $^{26}$ Behavioral and psychosocial correlates of nonadherence in young adults include anxiety and depression, ${ }^{13,27}$ HIV-1-associated stigma and discrimination, lack of disclosure, feelings of invulnerability to the consequences of HIV-1 disease, ${ }^{9,28}$ alcohol and recreational drug use, ${ }^{27}$ and low socioeconomic status. ${ }^{29}$ These factors may mediate the observed association among younger age, nonadherence, and poor virologic outcomes.

Table 2. Sensitivity Analyses: Predictors of Failure to Achieve Viral Suppression

\begin{tabular}{|c|c|c|c|c|}
\hline \multirow[b]{2}{*}{ Covariate } & \multicolumn{2}{|l|}{ HIV-1 RNA >400 copies $/ \mathrm{ml}$} & \multicolumn{2}{|c|}{$\begin{array}{c}\text { All who achieved viral } \\
\text { suppression (>80 copies } / \mathrm{ml})\end{array}$} \\
\hline & Adjusted hazard ratio $(95 \%$ CI) & $\mathrm{p}$ & Adjusted hazard ratio $(95 \%$ CI) & $\mathrm{p}$ \\
\hline Age (per 5 years younger) & $1.04(1.01-1.09)$ & .01 & $1.08(1.03-1.11)$ & $<.001$ \\
\hline $\begin{array}{l}\text { Partnership duration (years) } \\
\quad \geq 1 \\
\quad<1\end{array}$ & $\begin{array}{c}\text { Referent } \\
1.19(0.92-1.53)\end{array}$ & .18 & $\begin{array}{c}\text { Referent } \\
1.17(0.92-1.49)\end{array}$ & .21 \\
\hline $\begin{array}{l}\text { Monthly income } \\
\text { Any } \\
\text { None }\end{array}$ & $\begin{array}{c}\text { Referent } \\
1.15(0.99-1.34)\end{array}$ & .06 & $\begin{array}{c}\text { Referent } \\
1.12(0.98-1.28)\end{array}$ & .11 \\
\hline $\begin{array}{l}\text { Pretreatment CD4 count (cel } \\
\quad>250 \\
\leq 250\end{array}$ & $\begin{array}{c}\text { Referent } \\
1.21(1.06-1.37)\end{array}$ & .004 & $\begin{array}{c}\text { Referent } \\
1.21(1.07-1.38)\end{array}$ & .002 \\
\hline $\begin{array}{l}\text { Pretreatment HIV-1 RNA } \\
\quad\left(\text { per } \log _{10} \text { copies } / \mathrm{ml}\right)\end{array}$ & $1.12(1.03-1.23)$ & .008 & $2.19(2.04-2.34)$ & $<.001$ \\
\hline
\end{tabular}




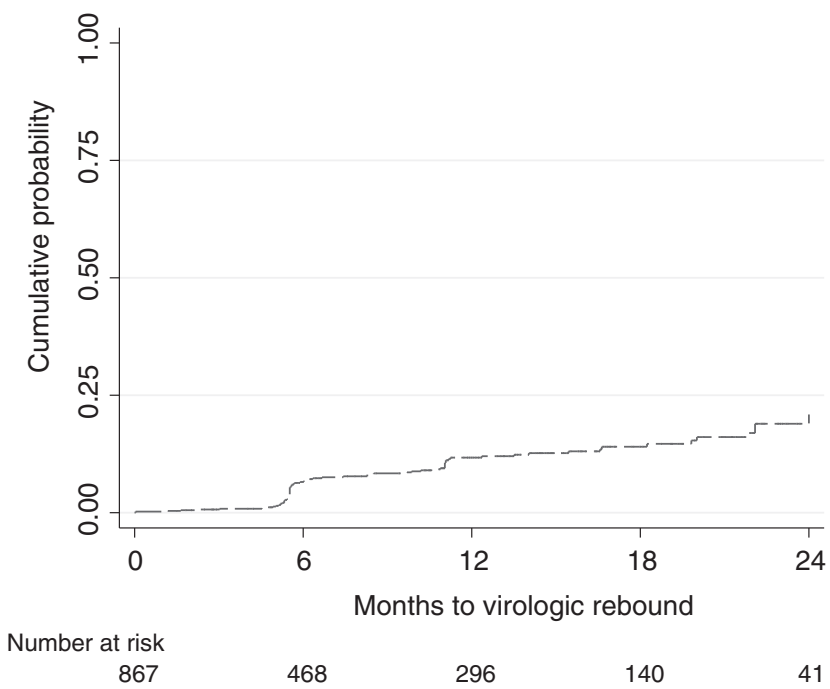

FIG. 3. Cumulative probability of virologic rebound following initial viral suppression.

Our finding that younger age predicts virologic rebound is consistent with prior studies, which reported lower risk of viral rebound with older age ${ }^{30,31}$ and a significantly shorter time to viral rebound in younger adults (20-29 years) compared with older ( $\geq 30$ years). ${ }^{32}$ In a prospective study of 1,305 HIV-1-infected persons on ART in British Columbia, younger age was independently associated with viral rebound after initial viral suppression. ${ }^{33}$ Predictors of nonadherence in subSaharan Africa include higher pill burden (twice-daily regimens vs. once-daily regimens), ${ }^{34}$ stavudine-containing regimens, ${ }^{35}$ geographic or transportation-related barriers, ${ }^{36}$ and Global Positioning System measured distance from home to clinic. ${ }^{37}$ In multiple settings, younger age predicts virologic rebound, and clinicians and ART programs should more effectively address behavioral, structural, and psychosocial barriers to ART adherence and provide adherence support for younger HIV-infected persons initiating ART.

We previously reported that younger age predicted delayed ART initiation in this cohort. ${ }^{16}$ In contrast, a South African study found no age difference between ART initiators and refusers. ${ }^{38}$ Delayed ART initiation is common in sub-Saharan Africa ${ }^{39-42}$ and results from health system, provider, and patient-level factors. ${ }^{41,43-46}$ Individuals who delay ART initiation may not be motivated to achieve the high level of adherence needed to achieve and sustain viral suppression $^{47}$ or may have competing priorities, less stable lives, and less familiarity or experience with daily treatment. Our finding that younger age predicts ART noninitiation, delays in achieving viral suppression, and virologic rebound points to a common theme related to ART barriers. Patient-level barriers to ART initiation are often similar to adherence barriers and include denial of the need to start treatment, lack of motivation to stay on treatment, fear of side effects, lack of social support, stigma, fear of disclosure, and the perception that starting ART signifies AIDS and impending mortality. ${ }^{41,46-52}$ Lower mental health scores were the only psychosocial variable significantly associated with poor adherence in a randomized trial of ART for HIV-1 prevention (HPTN 052). ${ }^{53}$ These factors may influence adherence during the initial period after ART initiation, as well as subsequent virologic outcomes. Durable viral load suppression is the ultimate goal of ART, both for individual health outcomes and for treatment as prevention. Addressing adherence barriers is a key to improving virologic outcomes in younger adults. Evidence-based interventions to improve adherence include once-daily regimens, fixed-dose combinations, reminder devices, mobile health technology, and provision of one-on-one or couple-based adherence support with feedback about viral suppression. ${ }^{53,54}$

The strengths of our study include the prospective design, large sample size, the diversity of a multinational cohort specifically of HIV-1-infected persons with known HIV-1uninfected partners, regular clinical and laboratory monitoring of HIV-1-infected participants, and robustness of results in sensitivity analyses. Limitations of the analysis include time-limited follow-up after ART initiation, lack of in-depth psychometric surveys to understand the bases for adherence and nonadherence, and reasons for nonadherence in real time, since viral load testing was conducted after the end of the study. We evaluated participants who were alive and on treatment at the time viral suppression was assessed (on-treatment analysis) and may have overestimated the effectiveness of ART. However, nearly, all HIV-1-infected partners were retained in study follow-up and, thus, our results are unlikely to be influenced by selection bias due to attrition and death.

In conclusion, the majority of heterosexual East African HIV-1-infected persons with known HIV-1-uninfected partners achieved viral suppression. Younger age independently predicted delayed ART initiation, failure to achieve viral suppression, and virologic rebound in this cohort. ART programs should give special consideration to motivating adherence and sustaining viral suppression in younger HIV-1infected persons in serodiscordant partnerships. Future studies should develop, test, implement, and rigorously evaluate evidence-based interventions to improve ART adherence in young adults and assess their correlation with virologic outcomes.

\section{Acknowledgments}

We are grateful to the study participants for their participation and dedication.

\section{Funding Source and Disclaimer}

This study was supported through research grants from the Bill \& Melinda Gates Foundation (Grant OPP47674) and the National Institute of Mental Health of the US National Institutes of Health (Grant R01 MH095507).

\section{Role of the Funding Source}

The authors designed and executed the study, had full access to the raw data, performed all analyses, wrote the article, and had final responsibility for the decision to submit for publication. The funder had no role in design, data collection, analysis, interpretation, or writing of the report.

\section{Partners PrEP Study Team}

University of Washington Coordinating Center and Central Laboratories, Seattle: Connie Celum (Principal Investigator, Protocol Cochair), Jared M. Baeten (Medical Director, Protocol Cochair), Deborah Donnell (Protocol 
Statistician), Robert W. Coombs, Lisa Frenkel, Craig W. Hendrix, Jairam R. Lingappa, and M. Juliana McElrath.

Study sites and site principal investigators: Eldoret, Kenya (Moi University, Indiana University): Kenneth H. Fife and Edwin Were; Kabwohe, Uganda (Kabwohe Clinical Research Center): Elioda Tumwesigye; Jinja, Uganda (Makerere University, University of Washington): Patrick Ndase and Elly Katabira; Kampala, Uganda (Makerere University): Elly Katabira and Allan Ronald; Kisumu, Kenya (Kenya Medical Research Institute, University of California, San Francisco): Elizabeth Bukusi and Craig R. Cohen; Mbale, Uganda (The AIDS Support Organization, CDC-Uganda): Jonathan Wangisi, James D. Campbell, and Jordan W. Tappero; Nairobi, Kenya (University of Nairobi, University of Washington): James Kiarie, Carey Farquhar, and Grace John-Stewart; Thika, Kenya (University of Nairobi, University of Washington): Nelly R. Mugo; Tororo, Uganda (CDC-Uganda, The AIDS Support Organization): James D. Campbell, Jordan W. Tappero, and Jonathan Wangisi.

Data management was provided by the DF/Net Research, Inc. (Seattle, USA), and site laboratory oversight was provided by the Contract Laboratory Services (CLS) of the Wits Health Consortium (University of the Witwatersrand, Johannesburg, South Africa).

Study medication was donated by the Gilead Sciences.

\section{Author Contributions}

A.M. and J.M.B. designed the study and wrote the first draft. A.M. performed the statistical analyses. All authors contributed to data collection, interpretation of the results, and the writing of the article, and all approved the final draft.

\section{Author Disclosure Statement}

No competing financial interests exist.

\section{References}

1. Joint United Nations Programme on HIV/AIDS. The Gap Report.UNAIDS, Geneva, 2014.

2. Quinn TC, Wawer MJ, Sewankambo N, et al.: Viral load and heterosexual transmission of human immunodeficiency virus type 1. Rakai Project Study Group. N Engl J Med 2000;342:921-929.

3. Baeten JM, Kahle E, Lingappa JR, et al.: Genital HIV-1 RNA predicts risk of heterosexual HIV-1 transmission. Sci Transl Med 2011;3:77ra29.

4. Cohen MS, Chen YQ, McCauley M, et al.: Prevention of HIV-1 infection with early antiretroviral therapy. N Engl J Med 2011;365:493-505.

5. Thompson MA, Aberg JA, Cahn P, et al.: Antiretroviral treatment of adult HIV infection: 2010 recommendations of the International AIDS Society-USA panel. JAMA 2010; 304:321-333.

6. WHO. Guidance on couples HIV testing and counselling including antiretroviral therapy for treatment and prevention in serodiscordant couples: Recommendations for a public health approach. 2012.

7. Garcia de Olalla P, Knobel H, Carmona A, Guelar A, Lopez-Colomes JL, Cayla JA: Impact of adherence and highly active antiretroviral therapy on survival in HIVinfected patients. J Acquir Immune Defic Syndr 2002;30: 105-110.
8. Carrieri MP, Raffi F, Lewden C, et al.: Impact of early versus late adherence to highly active antiretroviral therapy on immuno-virological response: A 3-year follow-up study. Antivir Ther 2003;8:585-594.

9. Ryscavage P, Anderson EJ, Sutton SH, Reddy S, Taiwo B: Clinical outcomes of adolescents and young adults in adult HIV care. J Acquir Immune Defic Syndr 2011;58:193-197.

10. Glass TR, De Geest S, Weber R, et al.: Correlates of selfreported nonadherence to antiretroviral therapy in HIVinfected patients: The Swiss HIV Cohort Study. J Acquir Immune Defic Syndr 2006;41:385-392.

11. Golin CE, Liu H, Hays RD, et al.: A prospective study of predictors of adherence to combination antiretroviral medication. J Gen Intern Med 2002;17:756-765.

12. Mannheimer S, Friedland G, Matts J, Child C, Chesney M. The consistency of adherence to antiretroviral therapy predicts biologic outcomes for human immunodeficiency virus-infected persons in clinical trials. Clin Infect Dis 2002;34:1115-1121.

13. Gonzalez JS, Batchelder AW, Psaros C, Safren SA: Depression and HIV/AIDS treatment nonadherence: A review and meta-analysis. J Acquir Immune Defic Syndr 2011;58:181187.

14. Friedman MS, Marshal MP, Stall R, et al.: Associations between substance use, sexual risk taking and HIV treatment adherence among homeless people living with HIV. AIDS Care 2009;21:692-700.

15. Wood SA, Tobias C, McCree J: Medication adherence for HIV positive women caring for children: In their own words. AIDS Care 2004;16:909-913.

16. Mujugira A, Celum C, Thomas KK, et al.: Delay of antiretroviral therapy initiation is common in east african $\mathrm{HIV}$-infected individuals in serodiscordant partnerships. J Acquir Immune Defic Syndr 2014;66:436-442.

17. Baeten JM, Donnell D, Mugo NR, et al.: Single-agent tenofovir versus combination emtricitabine plus tenofovir for pre-exposure prophylaxis for HIV-1 acquisition: An update of data from a randomised, double-blind, phase 3 trial. Lancet Infect Dis 2014;14:1055-1064.

18. Mujugira A, Baeten JM, Donnell D, et al.: Characteristics of HIV-1 serodiscordant couples enrolled in a clinical trial of antiretroviral pre-exposure prophylaxis for HIV-1 prevention. PLoS One 2011;6:e25828.

19. Kahle EM, Kashuba A, Baeten JM, et al.: Unreported antiretroviral use by HIV-1-infected participants enrolling in a prospective research study. J Acquir Immune Defic Syndr 2014;65:e90-e94.

20. Baeten JM, Donnell D, Ndase $\mathrm{P}$, et al.: Antiretroviral prophylaxis for HIV prevention in heterosexual men and women. N Engl J Med 2012;367:399-410.

21. Sabin CA, Smith CJ, d'Arminio Monforte A, et al.: Response to combination antiretroviral therapy: Variation by age. AIDS 2008;22:1463-1473.

22. Mutevedzi PC, Lessells RJ, Rodger AJ, Newell ML: Association of age with mortality and virological and immunological response to antiretroviral therapy in rural South African adults. PLoS One 2011;6:e21795.

23. Kim SH, Gerver SM, Fidler S, Ward H: Adherence to antiretroviral therapy in adolescents living with HIV: Systematic review and meta-analysis. AIDS 2014;28:1945-1956.

24. Hinkin $\mathrm{CH}$, Hardy DJ, Mason KI, et al:: Medication adherence in HIV-infected adults: Effect of patient age, cognitive status, and substance abuse. AIDS 2004;18 Suppl 1:S19-S25. 
25. Cambiano V, Lampe FC, Rodger AJ, et al:: Long-term trends in adherence to antiretroviral therapy from start of HAART. AIDS 2010;24:1153-1162.

26. Haberer JE, Baeten JM, Campbell J, et al:: Adherence to antiretroviral prophylaxis for HIV prevention: A substudy cohort within a clinical trial of serodiscordant couples in East Africa. PLoS Med 2013;10:e1001511.

27. Reisner SL, Mimiaga MJ, Skeer M, Perkovich B, Johnson $\mathrm{CV}$, Safren SA: A review of HIV antiretroviral adherence and intervention studies among HIV-infected youth. Top HIV Med 2009;17:14-25.

28. Hadland SE, Milloy MJ, Kerr T, et al.: Young age predicts poor antiretroviral adherence and viral load suppression among injection drug users. AIDS Patient Care STDS 2012;26:274-280.

29. Peltzer K, Pengpid S: Socioeconomic factors in adherence to HIV therapy in low- and middle-income countries. J Health Popul Nutr 2013;31:150-170.

30. Weintrob AC, Fieberg AM, Agan BK, et al.: Increasing age at HIV seroconversion from 18 to 40 years is associated with favorable virologic and immunologic responses to HAART. J Acquir Immune Defic Syndr 2008;49:40-47.

31. Henrich TJ, Wood BR, Kuritzkes DR: Increased risk of virologic rebound in patients on antiviral therapy with a detectable HIV load <48 copies/mL. PLoS One 2012;7:e50065.

32. Nachega JB, Hislop M, Nguyen H, et al.: Antiretroviral therapy adherence, virologic and immunologic outcomes in adolescents compared with adults in southern Africa. J Acquir Immune Defic Syndr 2009;51:65-71.

33. Lima VD, Bangsberg DR, Harrigan PR, et al.: Risk of viral failure declines with duration of suppression on highly active antiretroviral therapy irrespective of adherence level. J Acquir Immune Defic Syndr 2010;55:460-465.

34. Nachega JB, Parienti JJ, Uthman OA, et al.: Lower pill burden and once-daily antiretroviral treatment regimens for HIV infection: A meta-analysis of randomized controlled trials. Clin Infect Dis 2014;58:1297-1307.

35. Kamya MR, Mayanja-Kizza H, Kambugu A, et al.: Predictors of long-term viral failure among ugandan children and adults treated with antiretroviral therapy. J Acquir Immune Defic Syndr 2007;46:187-193.

36. Lankowski AJ, Siedner MJ, Bangsberg DR, Tsai AC: Impact of geographic and transportation-related barriers on HIV outcomes in sub-Saharan Africa: A systematic review. AIDS Behav 2014;18:1199-1223.

37. Siedner MJ, Lankowski A, Tsai AC, et al.: GPS-measured distance to clinic, but not self-reported transportation factors, are associated with missed HIV clinic visits in rural Uganda. AIDS 2013;27:1503-1508.

38. Katz IT, Essien T, Marinda ET, et al:: Antiretroviral therapy refusal among newly diagnosed HIV-infected adults. AIDS 2011;25:2177-2181.

39. Zachariah R, Tayler-Smith K, Manzi M, et al.: Retention and attrition during the preparation phase and after start of antiretroviral treatment in Thyolo, Malawi, and Kibera, Kenya: Implications for programmes? Trans R Soc Trop Med Hyg 2011;105:421-430.

40. Parkes-Ratanshi R, Bufumbo L, Nyanzi-Wakholi B, et al: Barriers to starting ART and how they can be overcome: Individual and operational factors associated with early and late start of treatment. Trop Med Int Health 2010;15:1347-1356.

41. Kahn TR, Desmond M, Rao D, et al.: Delayed initiation of antiretroviral therapy among HIV-discordant couples in Kenya. AIDS Care 2013;25:265-272.
42. Barnabas RV, van Rooyen H, Tumwesigye E, et al.: Initiation of antiretroviral therapy and viral suppression after home HIV testing and counselling in KwaZulu-Natal, South Africa, and Mbarara district, Uganda: A prospective, observational intervention study. Lancet HIV 2014;1:e68-e76.

43. Ingle SM, May M, Uebel K, et al.: Outcomes in patients waiting for antiretroviral treatment in the Free State Province, South Africa: Prospective linkage study. AIDS 2010;24:2717-2725.

44. Dixon JG, Gibson S, McPake B, Maleta K: Antiretroviral therapy (ART) rationing and access mechanisms and their impact on youth ART utilization in Malawi. Malawi Med J 2011;23:48-54.

45. Stein J, Lewin S, Fairall L: Hope is the pillar of the universe: Health-care providers' experiences of delivering anti-retroviral therapy in primary health-care clinics in the Free State province of South Africa. Soc Sci Med 2007;64:954-964.

46. Guthrie BL, Choi RY, Liu AY, et al.: Barriers to antiretroviral initiation in HIV-1-discordant couples. J Acquir Immune Defic Syndr 2011;58:e87-e93.

47. Mills EJ, Nachega JB, Buchan I, et al.: Adherence to antiretroviral therapy in sub-Saharan Africa and North America: A meta-analysis. JAMA 2006;296:679-690.

48. Heffron R, Ngure K, Mugo N, et al.: Willingness of Kenyan HIV-1 serodiscordant couples to use antiretroviralbased HIV-1 prevention strategies. J Acquir Immune Defic Syndr 2012;61:116-119.

49. Curran K, Ngure K, Shell-Duncan B, et al.: 'If I am given antiretrovirals I will think I am nearing the grave': Kenyan HIV serodiscordant couples' attitudes regarding early initiation of antiretroviral therapy. AIDS 2014;28:227-233.

50. Ngarina M, Popenoe R, Kilewo C, Biberfeld G, Ekstrom AM: Reasons for poor adherence to antiretroviral therapy postnatally in HIV-1 infected women treated for their own health: Experiences from the Mitra Plus study in Tanzania. BMC Public Health 2013;13:450.

51. Brigido LF, Rodrigues R, Casseb J, et al.: Impact of adherence to antiretroviral therapy in HIV-1-infected patients at a university public service in Brazil. AIDS Patient Care STDS 2001;15:587-593.

52. Weiser S, Wolfe W, Bangsberg D, et al.: Barriers to antiretroviral adherence for patients living with HIV infection and AIDS in Botswana. J Acquir Immune Defic Syndr 2003;34:281-288.

53. Safren SA, Mayer KH, Ou SS, et al.: Adherence to early antiretroviral therapy: Results from HPTN 052, a phase III, multinational randomized trial of ART to prevent HIV-1 sexual transmission in serodiscordant couples. J Acquir Immune Defic Syndr 2015;69:234-240.

54. Thompson MA, Mugavero MJ, Amico KR, et al:: Guidelines for improving entry into and retention in care and antiretroviral adherence for persons with HIV: Evidencebased recommendations from an International Association of Physicians in AIDS Care panel. Ann Intern Med 2012;156:817-833, w-284, w-285, w-286, w-287, w-288, w-289, w-290, w-291, w-292, w-293, w-294.

Address correspondence to: Andrew Mujugira International Clinical Research Center Department of Global Health

University of Washington Box 359927, 325 Ninth Avenue Seattle, WA 98104

E-mail: mujugira@uw.edu 